\title{
Separation of Benzene, Toluene, Ethylbenzene and P-Xylene from Aqueous Solutions by Carbon Nanotubes/Polyvinylidene Fluoride Nanocomposite Membrane
}

\author{
Fengsheng Su${ }^{1}$, Chungsying Lu², Jie-Huei Tai ${ }^{2}$ \\ ${ }^{1}$ Department of Safety, Health and Engineering, Ming Chi University of Technology, Taiwan \\ ${ }^{2}$ Department of Environmental Engineering, National Chung Hsing University, Taiwan \\ Email: *sfs0331@gmail.com
}

How to cite this paper: $\mathrm{Su}, \mathrm{F} . \mathrm{S} ., \mathrm{Lu}, \mathrm{C}$. and Tai, J.-H. (2016) Separation of Benzene, Toluene, Ethylbenzene and P-Xylene from Aqueous Solutions by Carbon Nanotubes/ Polyvinylidene Fluoride Nanocomposite Membrane. Journal of Water Resource and Protection, 8, 913-928.

http://dx.doi.org/10.4236/jwarp.2016.810075

Received: August 15, 2016

Accepted: September 23, 2016

Published: September 27, 2016

Copyright $\odot 2016$ by authors and Scientific Research Publishing Inc. This work is licensed under the Creative Commons Attribution International License (CC BY 4.0).

http://creativecommons.org/licenses/by/4.0/

\begin{abstract}
Carbon nanotubes/polyvinylidene fluoride (PVDF) nanocomposite membranes (abbreviated as CPMs) were fabricated to study their physicochemical property and separation efficiency of organic pollutants such as benzene, toluene, ethylbenzene and methylbenzene (abbreviated as BTEX) from aqueous solutions. The rejection coefficients $(R)$ of BTEX depend on the CNT content of CPM, pore size of membrane, molecule size of BTEX, permeation pressure $(P)$, feed concentration $\left(C_{\mathrm{f}}\right)$ and temperature. The CNT contents were 5\%, 10\% and 15\% in CPM have been conducted. The $10 \%$ CNT content of CPM (10-CPM) has not only higher water flux but also the relatively higher $R$ as comparing of 5\% and 15\% CNT of CPM. The $R$ decreased with increasing $P, C_{f}$ and temperature but has no significant influence on ionic strength $(\mu)$. The $\mathrm{R}$ of BTEX were found in the order as $\mathrm{B}<\mathrm{T}<\mathrm{E} \approx \mathrm{X}$ which revealed the major mechanism of BTEX separation with CPM was related to molecule size of $\mathrm{BTEX}(\mathrm{B}<\mathrm{T}<\mathrm{E} \approx \mathrm{X})$. It exhibits that the size exclusion plays the important role in BTEX separation. According to the result of separation of BTEX by 10-CPM, the $R$ of BTEX not only have above $80 \%$ with relative lower pressure but also have higher water flux as compared of other nano-filtration. This suggests that the 10-CPMs possess good potential for BTEX removal in wastewater treatment.
\end{abstract}

\section{Keywords}

CNT Membrane, BTEX, Nanofiltration

\section{Introduction}

The BTEX, volatile organic compounds, which are benzene (B), toluene (T), ethylben- 
zene (E) and p-xylene (X) are commonly used as solvents in industrial field. The wastewater containing of BTEX is usually discharged into environment from manufacturing, transportation and purposeful disposal sources. The BTEX are toxic and carcinogenic substances, while the presence of excessive amounts of BTEX in aqueous system may have an adverse impact on water quality or them volatized into ambient atmosphere thus endanger public health. It is clear that sustainable, cost effective and efficient wastewater treatment for BTEX is needed. The development of a cost-effective wastewater treatment process for BTEX removal before releasing into the environment is needed in order to meet the growing demand for cleaner water. Membrane filtration process has been employed for this purpose [1].

Carbon nanotubes (CNT) are unique, one-dimensional macromolecules that possess outstanding gas and water permeability, nanofluidics and molecular transport at nanoscales [2]-[5]. Literatures have demonstrated that the CNT membrane has extremely high transport rates of water and gas due to its unique nano-fluidic system [6]-[14]. These properties lead membrane filtration to high flux and low operation pressure and thus directly benefit the fields of water and wastewater treatment, desalination, gas pollution control, gas/chemical separations and drug delivery [13]-[19]. However, to the knowledge of the authors, filtration of BTEX from aqueous solutions by CNT/ polymer nanocomposite membrane is still limited in the literature.

This article fabricated the CNT/polyvinylidene fluoride (PVDF) nanocomposite membranes (CPMs) to study their physicochemical properties and separation performance of BTEX from aqueous solutions.

\section{Materials and Methods}

\subsection{Preparation of Carbon Nanotubes Membranes}

Commercially available multiwalled CNTs ( $\mathrm{C}_{\text {Tube }}-100$, CNT Co. Ltd., Korea) with outer diameter of $10-40 \mathrm{~nm}$ and length of $1-25 \mu \mathrm{m}$ were used to make CNT nanocomposite membranes which has $3.16 \mathrm{~nm}$ as average pore diameter. The CPMs were prepared by dissolving CNTs into $16 \mathrm{~mL}$ of N, N-dimethylformide (DMF, 99.8\% purity, Sigma Aldrich Corp., Mo, USA) at $25^{\circ} \mathrm{C}$ and sonicating for $1 \mathrm{~h}$. The PVDF (Sigma-Aldrich Corp, Mo, USA) was added into the mixture in a CNT/PVDF ratio of 5 - $15 \mathrm{wt} \%$ and then was stirred at $400 \mathrm{rpm}$ and heated to $180^{\circ} \mathrm{C}$ for $24 \mathrm{~h}$ to make sure complete dissolution of the polymer. The CNT/PVDF solution was uniformly casted on a glass plate by means of a hand-casting knife with a knife gap set at $300 \mu \mathrm{m}$ and then subsequently immersed in a deionized water bath to preserve the membrane (wet phase inversion method). The CPMs were trimmed to a circle shape with a diameter of $7 \mathrm{~cm}$. The PVDF membrane (PM) was also prepared using the same procedure with the exception of CNTs addition.

\subsection{Pollutants}

The employed B, T, E and X were analytical grade with $>99 \%$ purity and purchased from Merck (Darmstadt, Germany for B and T; Hohenbrunn, Germany for E and X). 
These chemical agents were diluted using deionized $\mathrm{H}_{2} \mathrm{O}$ to the desired concentrations in enclosed bottles. The molecule diameters of $\mathrm{B}, \mathrm{T}, \mathrm{E}$ and $\mathrm{X}$ are respectively $0.58,0.6$, 0.63 and $0.63 \mathrm{~nm}[20]$.

\subsection{Filtration Experiments}

Figure 1 shows the membrane filtration experiment setup. It was conducted by using a crossflow filtration system, which equipped with a pressure vessel containing the membrane module, pressurization tank, a temperature control box and a digital analytical balance. The BTEX containing solution was pressured by compressed air from the tank to the membrane cell within a stainless steel disk, which has inner diameter of $5 \mathrm{~cm}$ and an active area of $19.63 \mathrm{~cm}^{2}$. The permeation was analyzed for the BTEX concentration and weight to measure the permeation volume. The rejection coefficient of the BTEX concentration, $R$, was calculated as:

$$
R=\frac{C_{f}-C_{p}}{C_{f}}
$$

where $C_{f}$ and $C_{p}$ are the BTEX concentrations in the feed and permeate, respectively. The membrane is completely permeable when $R$ reaches zero while the membrane is completely impermeable when $R$ achieves unity.

\subsection{Analytic Methods}

The concentrations of BTEX were determined by a gas chromatograph and flame ionization detection (GC-FID, Model Shimadzu 2010, Shimadzu Instruments, CA, USA). The BTEX samples were collected to $5 \mathrm{ml}$ from filter and then injected to purge and trap concentrator (Stratum PTC, Teledyne Tekmar, OH, USA) under trap adsorption temperature at $25^{\circ} \mathrm{C}$ and trap desorption temperature at $250^{\circ} \mathrm{C}$ with $\mathrm{N}_{2}$ as purge gas, then the gaseous BTEX were injected to GC-FID for analysis at detector temperature of $200^{\circ} \mathrm{C}$.

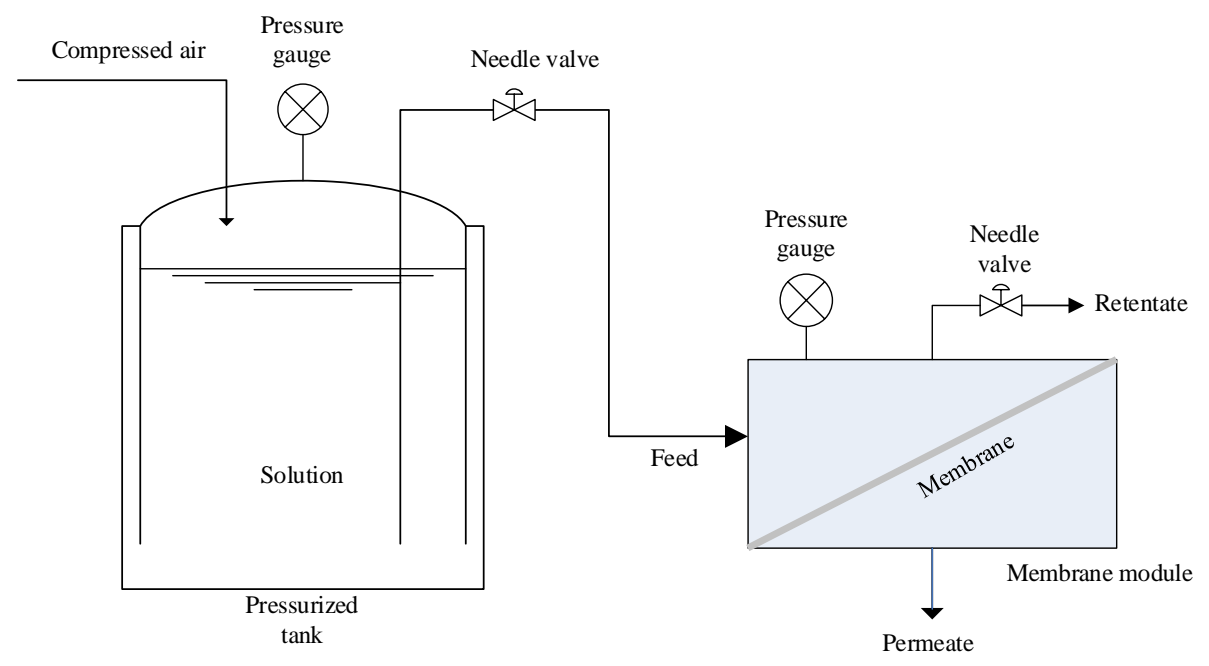

Figure 1. Membrane filtration setup. 
The CNT content of CPMs was determined by a thermo gravimetric analyzer (TGA I 1000 , Instrument Specialists Incorporated, Twin Lakes, WI, USA) at a heating rate of $2^{\circ} \mathrm{C} / \mathrm{min}$ from $25^{\circ} \mathrm{C}-800^{\circ} \mathrm{C}$.

The morphologies of the PM and CPMs were investigated by a field emission scanning electron microscope (FE-SEM, Ultra Plus, Carl Zeiss SMT AG, Germany). Representative samples of the membranes were cut into $1-2 \mathrm{~mm}^{2}$, attached with carbon tape to aluminum stabs, and shadowed with platinum prior to the SEM measurements.

Membrane surface topography was determined by atomic force microscope (AFM, SPA 400, Seiko Instruments Inc., Japan) image and analysis. Topographic imaging was performed in dynamic force mode with noncontact silicon cantilevers (NSC15/AIBS, spring const. $=20 \mathrm{~N} / \mathrm{m}$, Mikromasch, Estonia). The surface roughness of membrane (abbreviated as $\mathrm{R}_{\mathrm{RMS}}$ ) that was typically used to quantify variations in surface elevation was determined directly from the height data by root-mean-square roughness calculation.

The pore properties of the membrane were determined by $\mathrm{N}_{2}$ adsorption/desorption at $77 \mathrm{~K}$ via Micromeritics ASAP 2020 volumetric sorption analyzer (Norcross, GA, USA). The $\mathrm{N}_{2}$ adsorption/desorption isotherms were measured at a relative pressure range of $0.0001-0.99$ and then employed to determine specific pore volume and average pore diameter via the micropore (MP) method for pore sizes below $1.7 \mathrm{~nm}$ and the Barrett-Johner-Halenda (BJH) method for pore sizes 1.7 - $300 \mathrm{~nm}$.

\section{Results and Discussion}

\subsection{Characterization of the Membrane}

\subsubsection{TGA}

Figure 2 shows the TG curves of PM and 5\% - 15\% of CNT content CPMs. There are two temperatures for the start of rapid weight loss, named as $T_{1}$ and $T_{2}$, which were

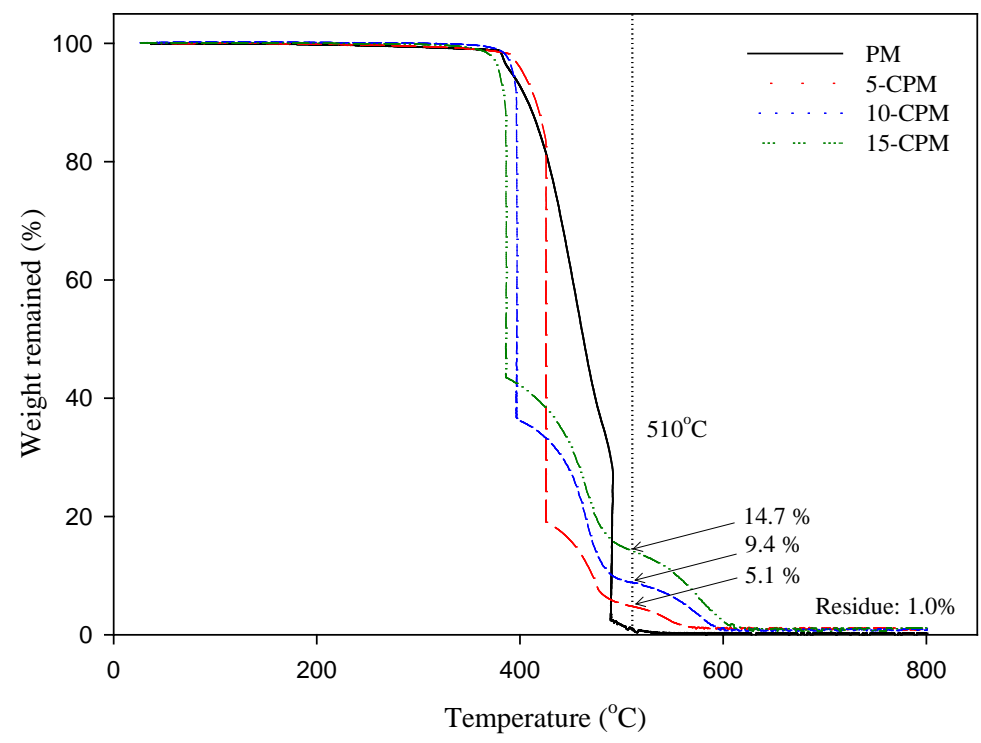

Figure 2. TG curves of PM and various CPMs. 
ascribed to initial temperatures for thermal decomposition of PVDF and CNTs/ash, respectively [21]. The $\mathrm{T}_{1}$ of $\mathrm{PM}, 5-\mathrm{CPM}, 10-\mathrm{CPM}$ and 15-CPM were in the range of $362^{\circ} \mathrm{C}-390^{\circ} \mathrm{C}$ and $\mathrm{T}_{2}$ of them was $510^{\circ} \mathrm{C}$. The CNTs starts thermal decomposition since $\mathrm{T}_{2}$ and the weight remained at $\mathrm{T}_{2}$ can explain to percentage of CNTs content in membrane. The remaining weight of 5, 10,15-CPMs at $\mathrm{T}_{2}$ was about 5.1, 9.4 and 14.7 $\mathrm{wt} \%$, respectively, which reveals that the real CNTs content in CPMs has well controlled in this research. The residue material at $800^{\circ} \mathrm{C}$ about $1.0 \mathrm{wt} \%$ could be attributed to ash and metallic catalytic from CNTs [22].

\subsubsection{Pore Size Distribution}

Figure 3 displays the pore size distributions of membranes with micropores $(<2 \mathrm{~nm})$, mesopores $(2-50 \mathrm{~nm})$ and macropores $(50-300 \mathrm{~nm})$. It can be seen that the PM has narrow micropores at $0.42 \mathrm{~nm}$ and has lower amount in mesopores/macropores volume. After adding CNTs into PM, the micropore size range has increased wider to 0.4 - $0.46 \mathrm{~nm}$ which can be attributed to the CNTs provided more pores from space of graphite interlayers in the range of $0.3-0.4 \mathrm{~nm}$ [23] [24]. The mesocopore/macropore volume of PM and CPMs were tenth of magnitude lower than micropore volumes of that. The CNTs content could effects mesocopore/macropore volume of CPM that has increased among of $5-70 \mathrm{~nm}$ with rising of CNT contents. It can be explained that the CNTs have a number of CNT cavity pores $(10 \mathrm{~nm})$ and aggregated pores $(40-60 \mathrm{~nm})$ which creating the pores in CPMs [25].

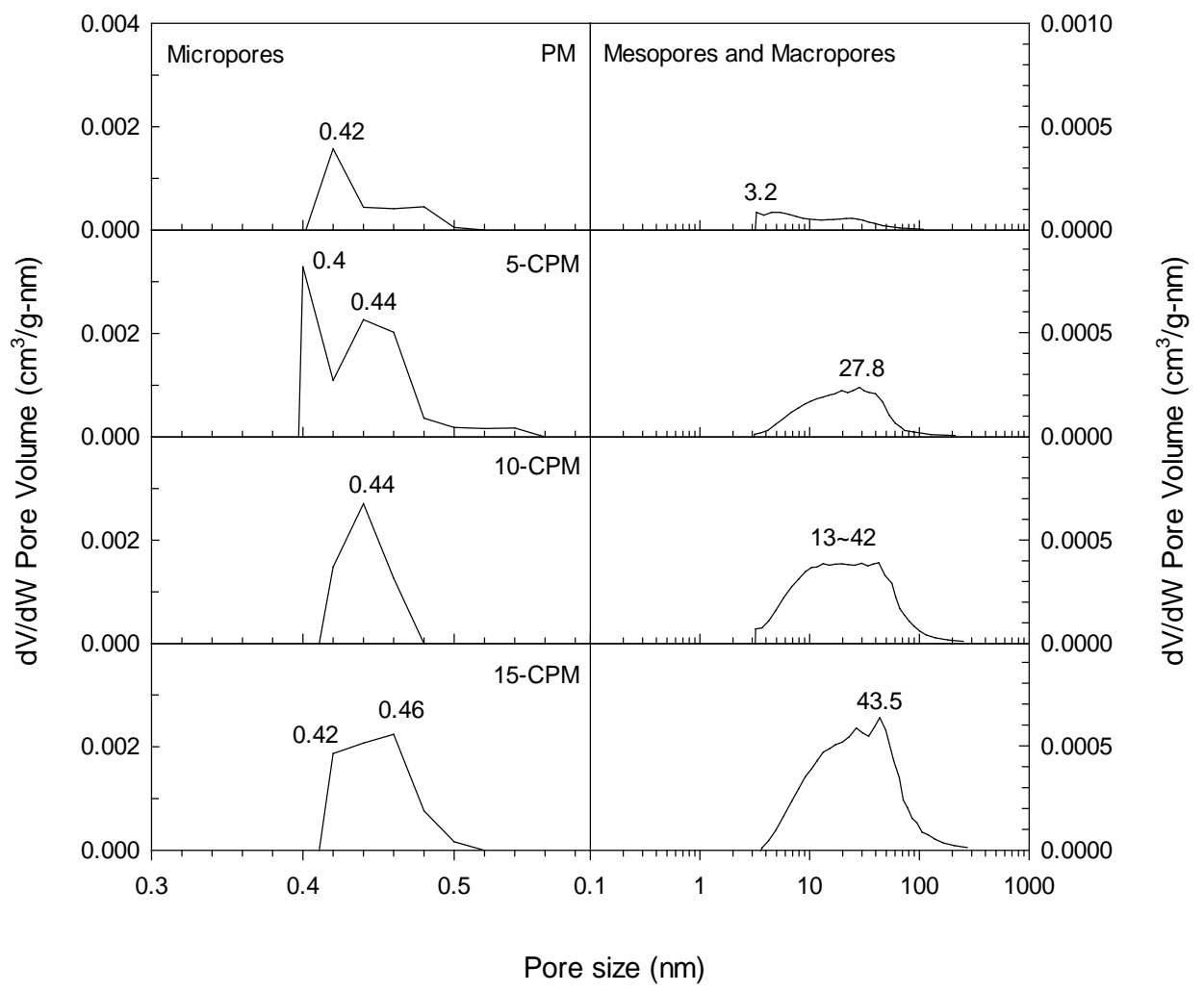

Figure 3. Pore size distributions of PM and various CPMs. 


\subsubsection{FE-SEM}

Figures 4(a)-(d) show the FE-SEM images of PM and CPMs surfaces. The PM surface can be seen smoother than CPMs surfaces. While the CNTs added into membranes, the membrane surface became rougher and created few surface macropores. The surface of all CPMs have obviously rugae-like structure that has space below $3 \mathrm{~nm}$ can be seen in Figure 4(b-1). The surface macropores were in the range of 10 - $25 \mathrm{~nm}$ for 5-CPM, 10 $35 \mathrm{~nm}$ for $10-\mathrm{CPMs}$ and $10-130 \mathrm{~nm}$ for $15-\mathrm{CPMs}$, respectively, which can prove the CNT content effects on pore size of CPMs. The surface macropore quantity was increased with increasing CNT contents, which can be attributed to the CNTs has aggregated structure and the remained air bubbles in the aggregated pores during CPMs fabrication.

\subsubsection{Membrane Surface Roughness ( $\mathrm{R}_{\mathrm{RMS}}$ )}

$\mathrm{R}_{\mathrm{RMS}}$ was measured by atomic force microscopy (AFM) which can explain the surface roughness of membrane and its relation of water permeation. The higher value of $R_{R M S}$ reveals the membrane surface is rougher, more hydrophilic, more pore density and more pore volume that are related to filtration performance of membrane [26]. Table 1 shows the $\mathrm{R}_{\mathrm{RMS}}$ roughness for PM and 5 - 15 CPMs membranes. The $\mathrm{R}_{\mathrm{RMS}}$ of PM was $35.6 \mathrm{~nm}$ which is lower than that of all CPMs. It's the fact that increasing the addition of CNTs in polymer membrane can greater the surface roughness and thus changed the filtration performance.

\subsubsection{Optical Contact Angle of Membranes $(\theta)$}

Table 2 shows the optical contact angle $(\theta)$ of PM and CPMs. The $\theta$ of PM was less
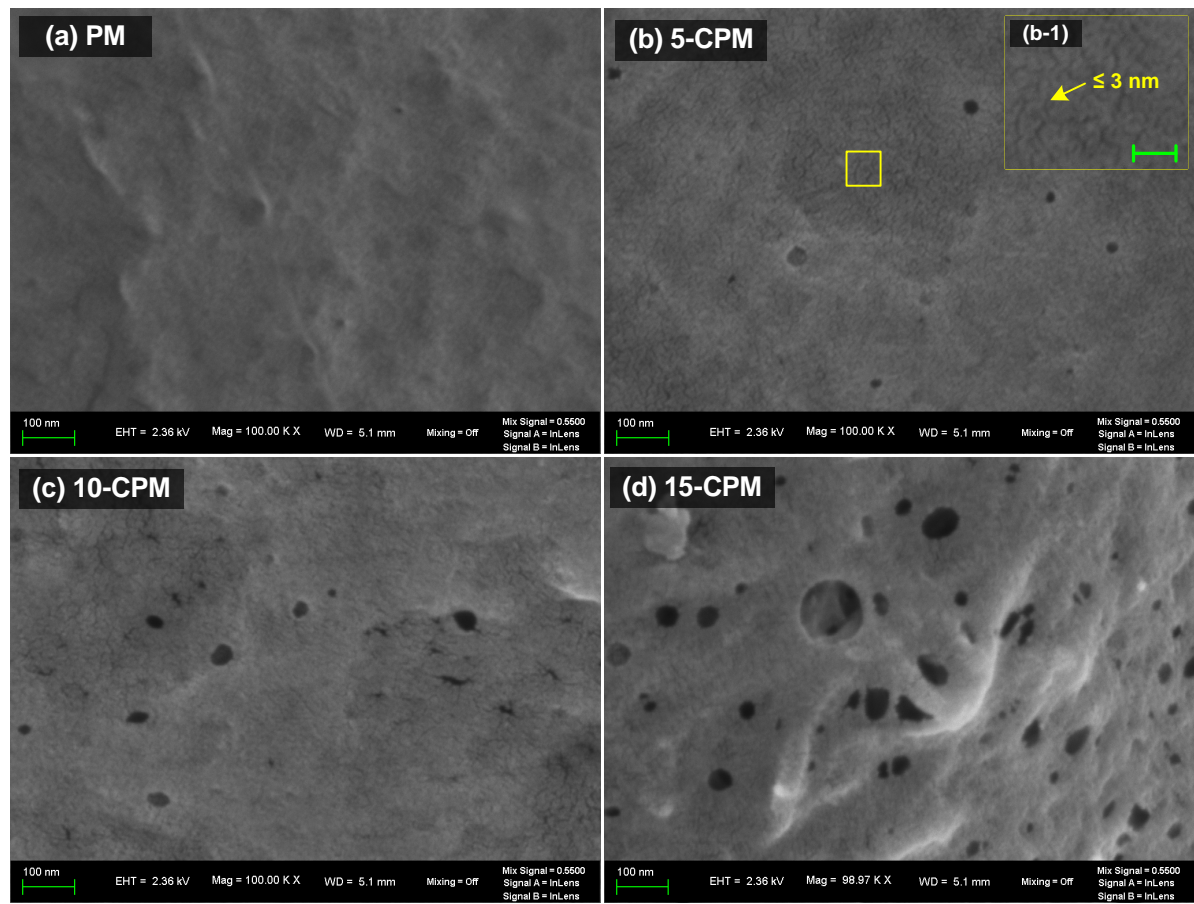

Figure 4. SEM images of PM and various CPMs. 
Table 1. Surface roughness of membranes.

\begin{tabular}{cc}
\hline Membranes & $\mathrm{R}_{\mathrm{RMS}}(\mathrm{nm})$ \\
\hline PM & 35.6 \\
$5-\mathrm{CPM}$ & 43.5 \\
$10-\mathrm{CPM}$ & 58.8 \\
$15-\mathrm{CPM}$ & 78.9 \\
\hline
\end{tabular}

Table 2. Optical contact angle of membranes.

\begin{tabular}{cc}
\hline Membrane & $\theta\left(^{\circ}\right)$ \\
\hline PM & $83.75 \pm 2.36$ \\
$5-\mathrm{CPM}$ & $76.07 \pm 0.7$ \\
$10-\mathrm{CPM}$ & $71.78 \pm 2.03$ \\
$15-\mathrm{CPM}$ & $59.95 \pm 1.46$ \\
\hline
\end{tabular}

than $90^{\circ}$ which reveals the PM has the hydrophilic surface and has good affinity for water [27]. The $\theta$ of CPM were decreased with increasing CNT content and $\mathrm{R}_{\mathrm{RMS}}$. It is the fact that the addition of CNT into membrane can enhance the hydrophilicity and roughness for membrane thus increasing the water permeation.

\subsection{Effect of CNTs Content on Water Permeation}

Figure 5 displays the water permeation flux $\left(J_{v}\right)$ of PM and all CPMs with operation time under permeation pressure $10 \mathrm{psi}$. The $J_{v}$ of PM and 5-CPM have stable $J_{v}$ from 10 to $420 \mathrm{~min}$, but that of $10-\mathrm{CPMs}$ and $15-\mathrm{CPMs}$ have decreased then reached equilibrium after $300 \mathrm{~min}$ and $420 \mathrm{~min}$, respectively. The decrease of $J_{V}$ for 10-CPM and $15-\mathrm{CPM}$ are the conventional trend which relating to pore structure of membrane. The large pore size and larger $\mathrm{R}_{\mathrm{RMS}}$ could cause the water molecular accumulated on membrane and thus reducing the $J_{r}$ The similar finding was reported in literatures [28] [29]. The $J_{V}$ at equilibrium time for PM, 5, 10, 15-CPMs are 2.0, 3.3, 4.6 and $7.1 \mathrm{~L} / \mathrm{m}^{2} \cdot \mathrm{h}$, respectively. It shows that all CPMs have greater $J_{V}$ than that of PM, which is a fact that more CNTs content can enhance more water permeability for membrane.

\subsection{Separation of BTEX}

\subsubsection{BTEX Removal}

Figure 6 exhibits the $R$ of PM and all CPMs at a $C_{\mathrm{f}}$ of $80 \mathrm{mg} / \mathrm{L}$ under pressure $10 \mathrm{psi}$. The $R$ of 5-CPM was slightly lower than that of PM for BTEX. The $R$ of PM and 5-CPM were respectively $97.4 \%, 94.3 \%, 82.6 \%$ and $73.8 \%$ for $\mathrm{B}, 99.9 \%, 97.6 \%, 87.2 \%$ and $79.8 \%$ for $\mathrm{T}, 99 \%, 97.9 \%, 89.6 \%$ and $85.0 \%$ for $\mathrm{E}, 99.2 \%, 97.7 \%, 90.7 \%$ and $84.7 \%$ for $\mathrm{X}$ at the equilibrium time $330 \mathrm{~min}$. It can be seen that the membranes follow the order of $\mathrm{PM}>$ 5-CPM $>10-\mathrm{CPM}>15-\mathrm{CPM}$ for BTEX and PM, 5-CPM and 10-CPM have $R$ above $80 \%$ but $15-\mathrm{CPM}$. This could be attributed to the increases of mesopoers/macropores from CNTs in 15-CPM resulting some BTEX molecules have penetrated through mem- 


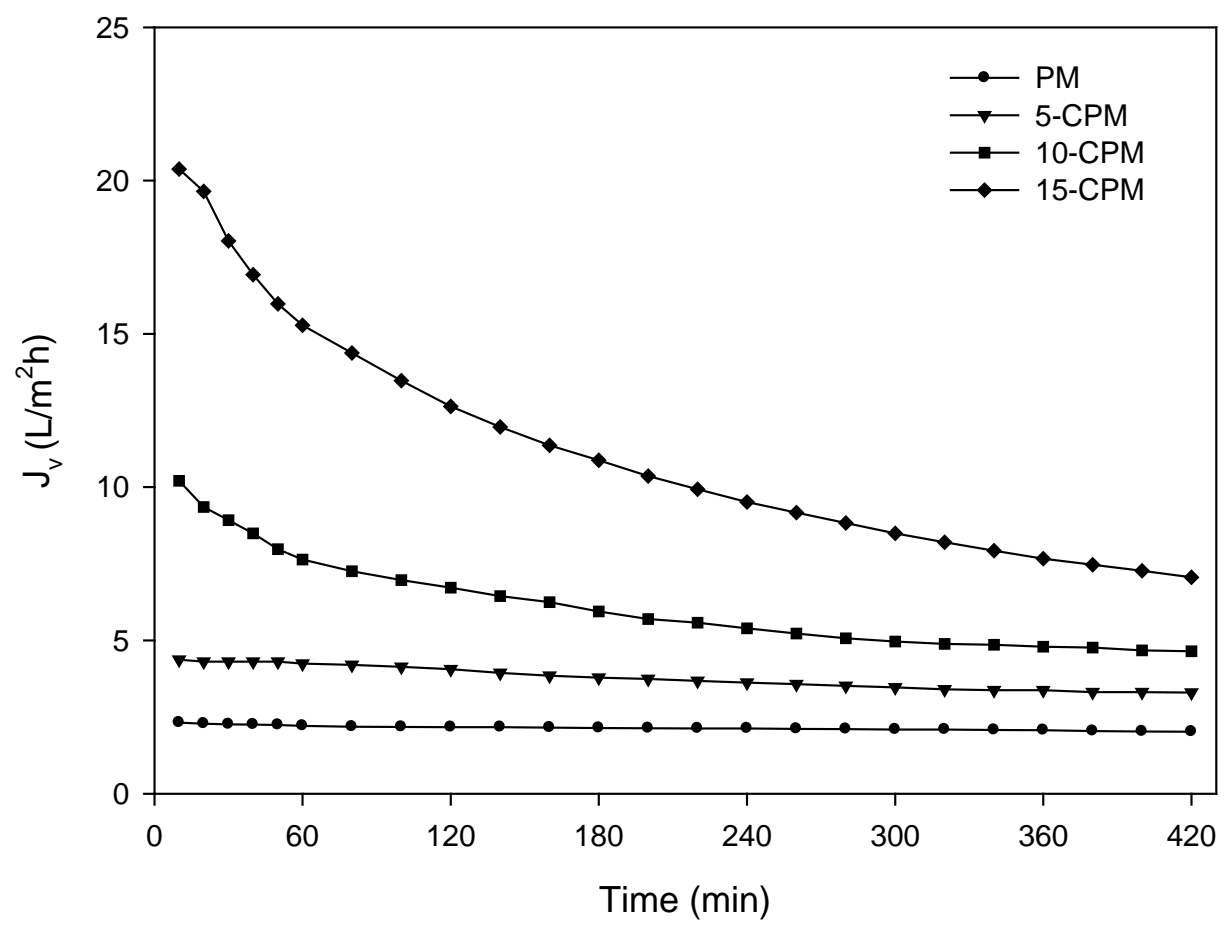

Figure 5. Water flux of PM and CPMs at 10 psi permeate pressure.

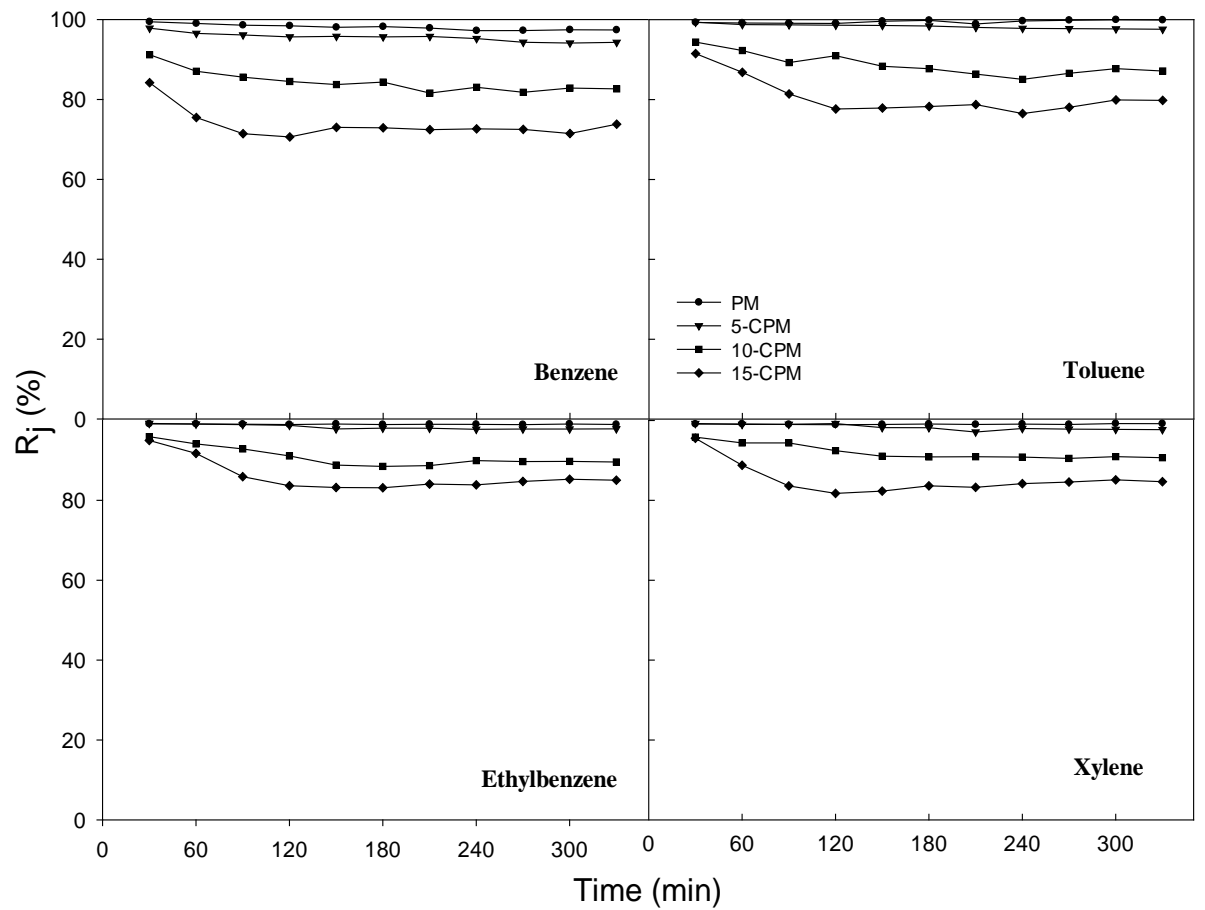

Figure 6. $R$ of BTEX with PM and CPMs.

brane and make higher CNT content membrane have lower BTEX rejection. The 10-CPM is not only has $R$ above $80 \%$ for BTEX, but also has greater $J_{V}$ than 5-CPM. Therefore, 10-CPM has been chosen to exam the following membrane studies. 


\subsubsection{Effect of Permeation Pressure}

Figure 7 shows the $R$ and $J_{\mathrm{v}}$ of 10-CPM under various permeation pressure $(P)$ from 5 40 psi with $C_{f}=80 \mathrm{mg} / \mathrm{L}$ of BTEX. The $R_{j}$ of BTEX has significant decreases with increasing of $P$, but $J_{V}$ of BTEX has increased with rising of $P$. The $R$ of BTEX were more than $90 \%$ while $P$ was less than 10 psi. Therefore, the $P$ at 10 psi was optimal pressure for membrane operation above $90 \%$ of $R$ for BTEX. The $R$ of B, T, E, X were $90.7 \%$, 93.4\%, 95.1\% and 95.4\%, respectively. This shows the order of $R$ for BTEX was B $<\mathrm{T}<$ $\mathrm{E} \approx \mathrm{X}$ that is consistent with the order of molecular weight and molecular size. It indicates that the separation performance of the BTEX from aqueous solutions with CPM is dependent on molecular physical property.

\subsubsection{Effect of Feed BTEX Concentrations}

Figure 8 displays the effect of $C_{\mathrm{f}}$ in 40,80 and $120 \mathrm{mg} / \mathrm{L}$ with $10-\mathrm{CPM}$ on $10 \mathrm{psi}$. The $R$ of BTEX $C_{f}$ in 40,80 and $120 \mathrm{mg} / \mathrm{L}$ at $180 \mathrm{~min}$ were $87.3 \%, 80.3 \%$ and $68.3 \%$ for B, $92.6 \%, 84.7 \%$ and $76.3 \%$ for $\mathrm{T}, 95.0 \%, 88.5 \%$ and $83.9 \%$ for E, $96.5 \%, 90.0 \%$ and $85.4 \%$

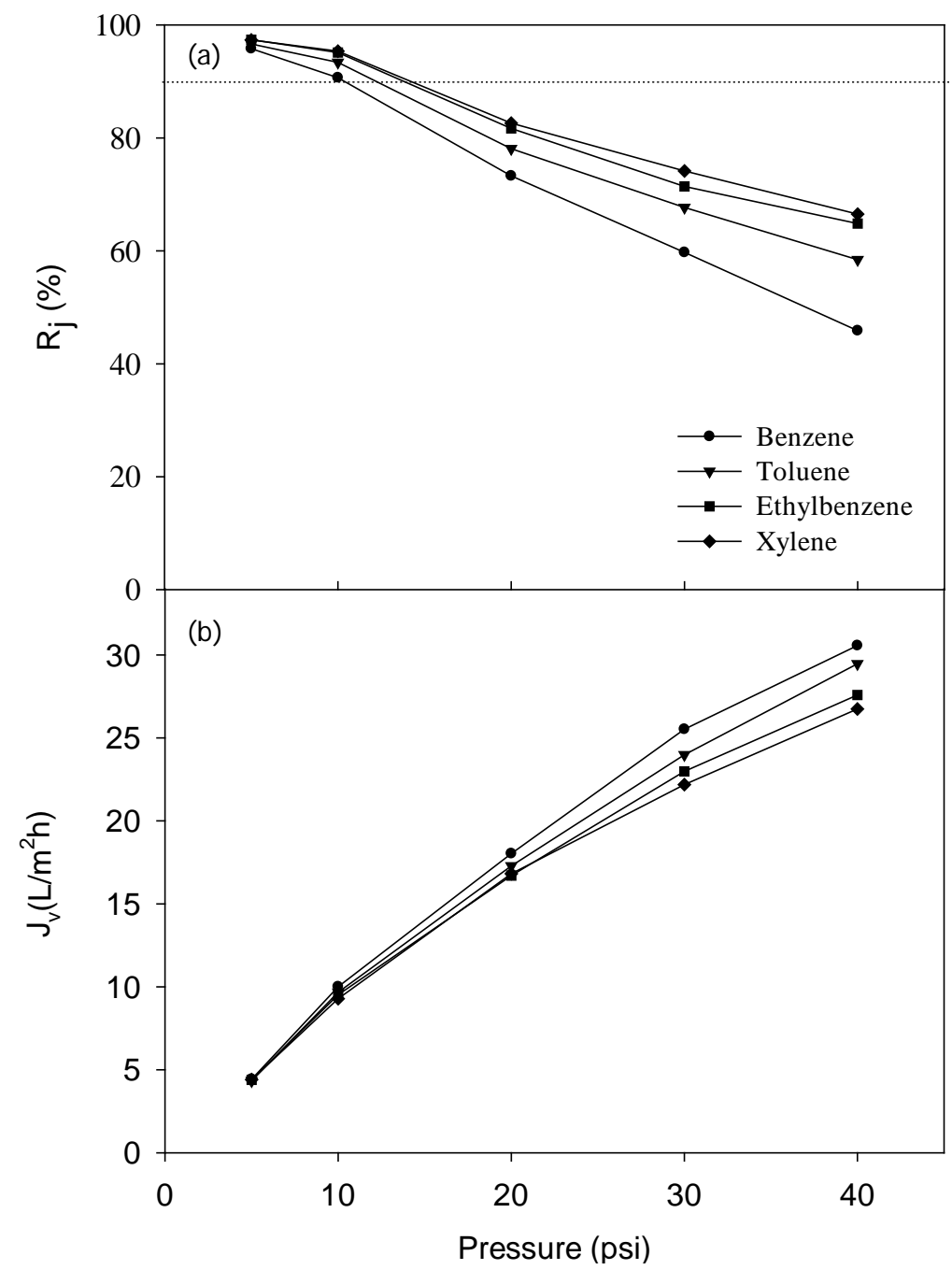

Figure 7. $R$ and $J_{V}$ of BTEX for $10-\mathrm{CPMs}$ under various permeation pressures. 


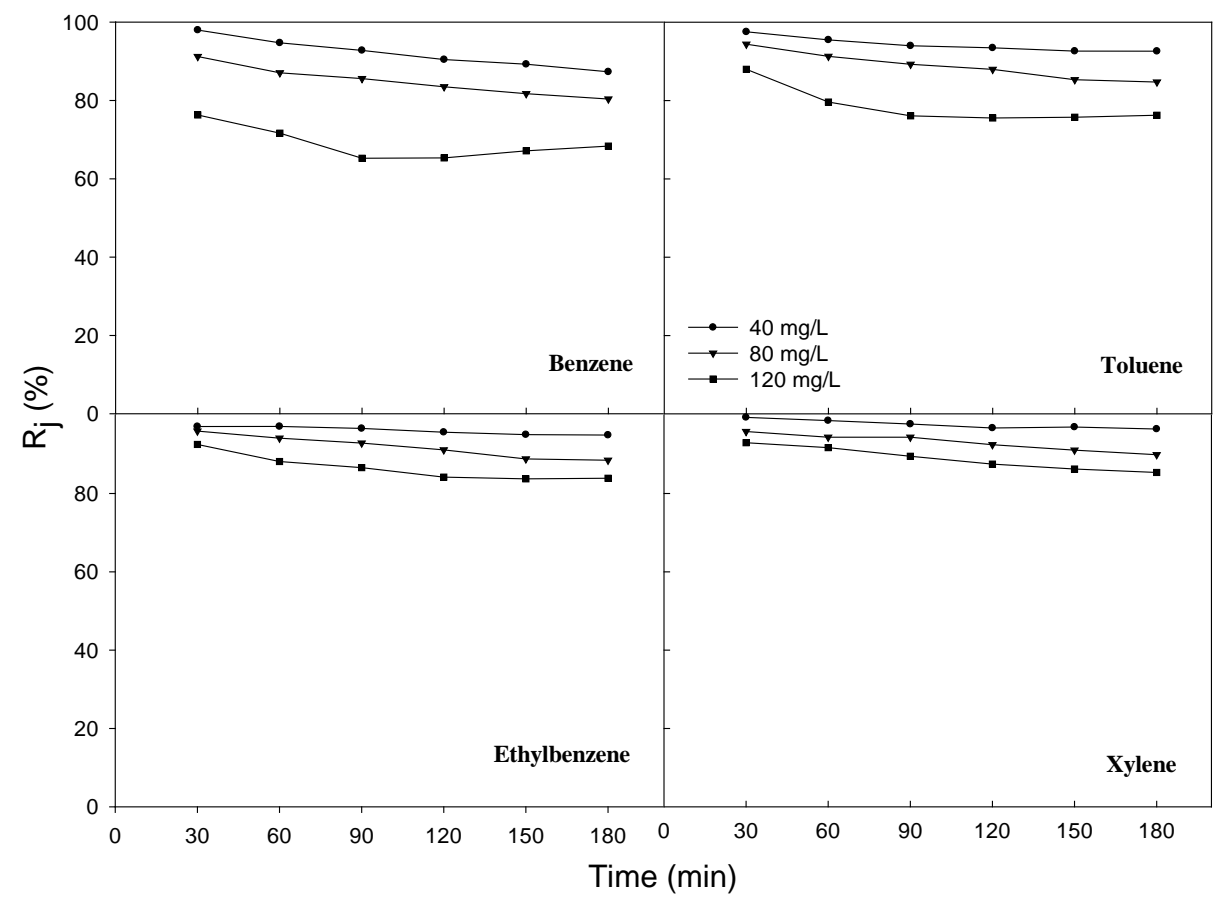

Figure 8. Effect of BTEX initial concentration on $R$ with 10-CPMs.

for X, respectively. The result shows that the $R$ of BTEX were decreased with increasing $C_{f}$ of BTEX. The reason is that the higher $C_{f}$ can enhance the diffusion force and cause the BTEX molecular to diffuse into membrane. The $R$ of BTEX have also decreased with filtration time, which can be attributed to the concentration accumulated on retentate side with time and then enhanced the diffusion force on membrane, thus reduced $R$. The $R$ has significant decrease in filtration of $\mathrm{B}$ and $\mathrm{T}$ as compared with $\mathrm{E}$ and $\mathrm{X}$ which reveals that the $\mathrm{B}$ and $\mathrm{T}$ have smaller molecular size and diffused into membrane easier.

\subsubsection{Effect of Solution Ionic Strength}

The $\mu$, which is a general property of the solution affecting the affinity between the solute and the aqueous solution, was adjusted using $\mathrm{NaCl}$ solution. The polar solutes can be affected by $\mu$ and adsorbed on membrane surface to become electrical double layer, which could increase the penetration of solutes [30]. Figure 9 exhibits the effects of solution ionic strength $(\mu)$ on the $R$ of $10-\mathrm{CPM}$ at a $C_{f}$ of $80 \mathrm{mg} / \mathrm{L}$ and $P$ of 10 psi. The $R$ of BTEX with $\mu$ in $0,10,100 \mathrm{mM}$ at $180 \mathrm{~min}$ were $80.3 \%, 80.3 \%$ and $72.6 \%$ for B, $84.7 \%$, $84.0 \%$ and $77.4 \%$ for $\mathrm{T}, 88.5 \%, 88.2 \%$ and $78.1 \%$ for $\mathrm{E}, 89.9 \%, 87.2 \%$ and $80 \%$ for $\mathrm{X}$, respectively. It is apparent that the $R$ with $10 \mathrm{mM}$ has similar result with that without $\mu$, but $R$ with $100 \mathrm{mM}$ was slightly lower $(<10 \%)$ than that without $\mu$. The result shows that the effect of $\mu$ on the $R$ was not significant for the $\mu$ below $100 \mathrm{mM}$.

\subsubsection{Effect of Solution Temperature}

Figure 10 exhibits the effects of solution temperature on the $R$ of $10-\mathrm{CPM}$ at a $C_{\mathrm{f}}$ of 80 $\mathrm{mg} / \mathrm{L}$ and $P$ of $10 \mathrm{psi}$. The $R$ of BTEX with temperature at $10^{\circ} \mathrm{C}, 20^{\circ} \mathrm{C}, 30^{\circ} \mathrm{C}$ at $180 \mathrm{~min}$ 


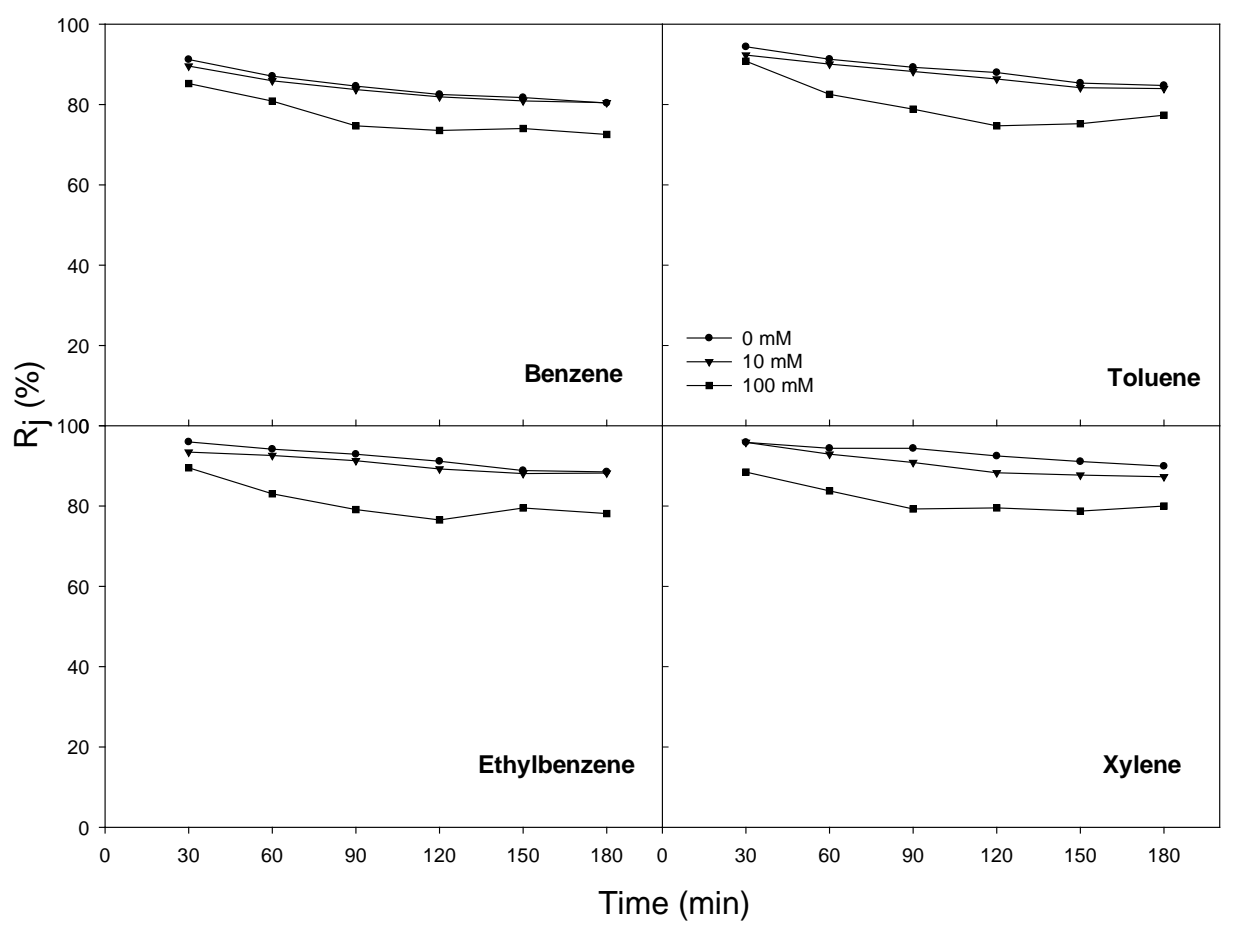

Figure 9. Effect of $\mu$ on $R$ of BTEX with 10-CPMs.



Figure 10. Effect of solution temperature on $R$ with 10-CPMs.

were $89.4 \%, 80.3 \%$ and $75.0 \%$ for $\mathrm{B}, 92.4 \%, 84.7 \%$ and $79.9 \%$ for $\mathrm{T}, 94.1 \%, 88.5 \%$ and $83.8 \%$ for $\mathrm{E}, 95.2 \%, 90.0 \%$ and $80.9 \%$ for $\mathrm{X}$, respectively. It's obviously that the $R$ of BTEX were decreased with increasing temperature, which is due to the thermal expan- 
sion of membrane that resultant the pore size enlarger in membrane thus reducing the $R$ of BTEX [31].

\subsection{Separation of Mixed BTEX}

Figure 11 exhibits the $R$ of mixed BTEX at a $C_{\mathrm{f}}$ of 20 and $80 \mathrm{mg} / \mathrm{L}$ with $10-\mathrm{CPM}$ at 10 psi. The $R$ of mixed B, T, E, X at 180 min were respectively $74.5 \%, 77.3 \%, 80.2 \%$ and $80.3 \%$ for $C_{\mathrm{f}}$ of $20 \mathrm{mg} / \mathrm{L}$ and $80.2 \%, 83.6 \%, 88.0 \%$ and $87.2 \%$ for $C_{\mathrm{f}}$ of $80 \mathrm{mg} / \mathrm{L}$. While the $C_{f}$ is $80 \mathrm{mg} / \mathrm{L}$, the $R$ of mixed BTEX is similar to that of individual BTEX (section 3.2.3) and following the same order $(\mathrm{B}<\mathrm{T}<\mathrm{E} \approx \mathrm{X})$ which indicating that the separation mechanism of BTEX can be assigned to size exclusion. The $J_{v}$ of mixed BTEX at a $C_{\mathrm{f}}$ of 20 and $80 \mathrm{mg} / \mathrm{L}$ on $180 \mathrm{~min}$ were decreased $21.4 \%$ and $34.7 \%$, respectively. It is the fact that the fouling has taken place by concentration on membrane surface and thus decreased the water flux.

\subsection{Separation Mechanism}

It is observed that the order of $R$ with CPMs was in order of 5-CPM $>10-\mathrm{CPM}>$ $15-\mathrm{CPM}$ is consistent with pore size and specific pore volume. The R of BTEX have effected by permeation pressure, inlet concentration and temperature but not influenced by ionic strength. This indicates that the separation performance of the BTEX from aqueous solutions with CPMs is dependent on size exclusion. The diagram of nanofluid in CPMs and major mechanism for rejecting BTEX from aqueous solutions is graphically presented in Figure 12. The water molecules penetrate through the CPMs with

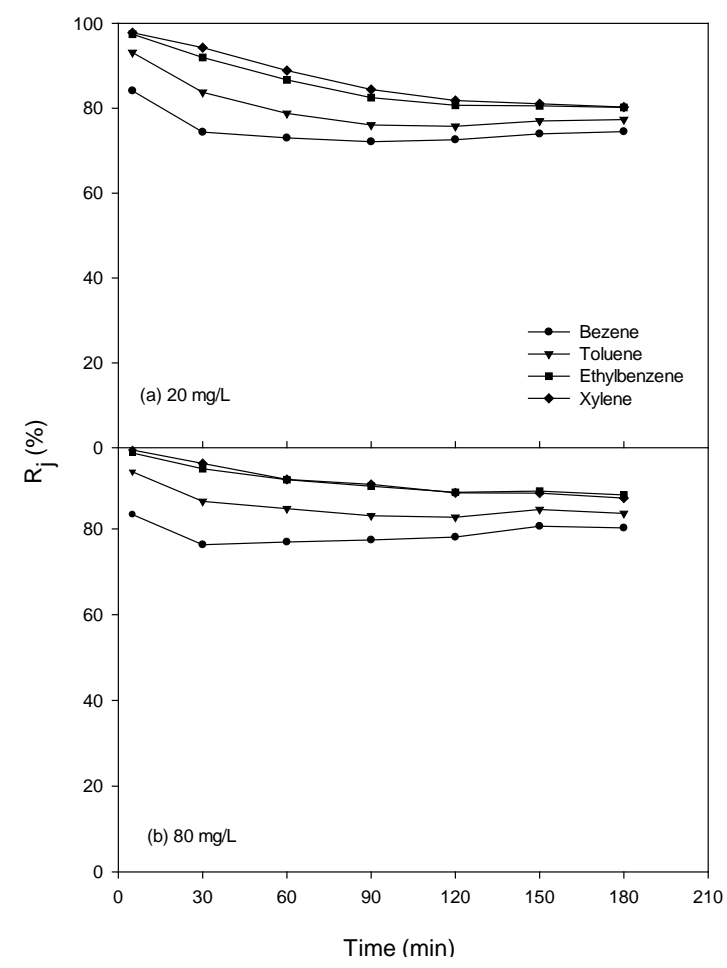

Figure 11. Filtration of mixed BTEX with CPMs. 


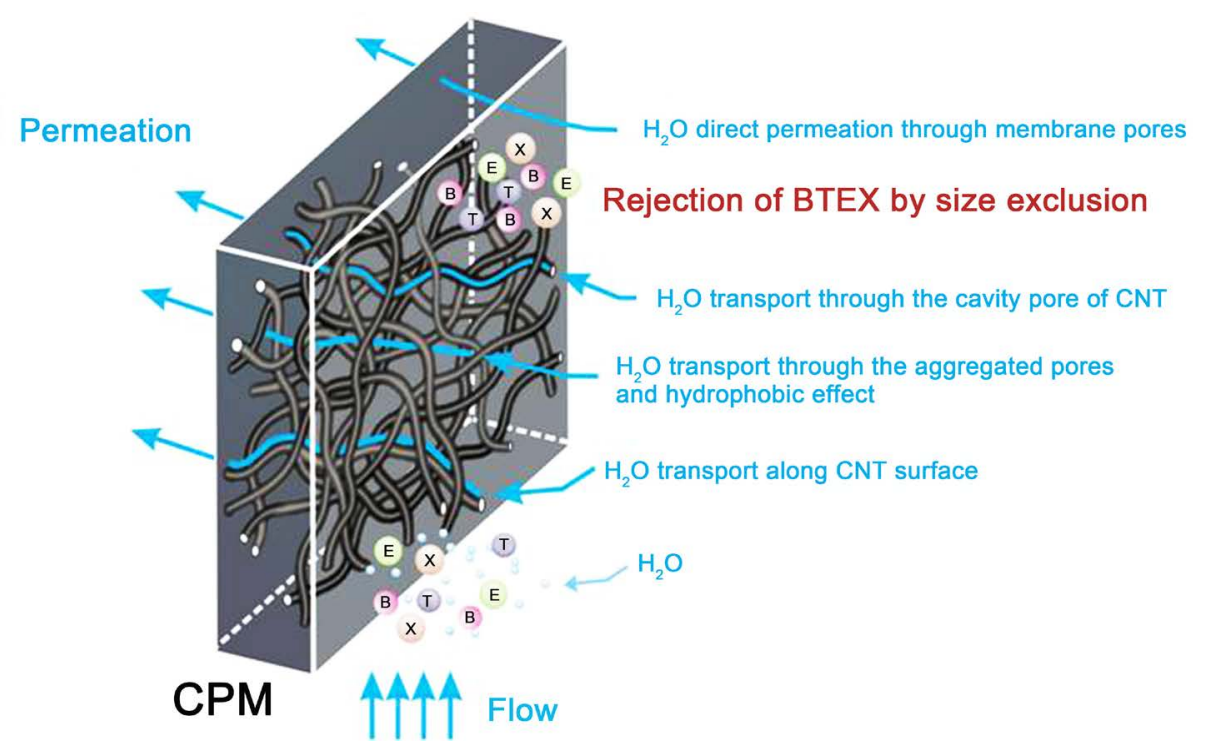

Figure 12. Schematic diagram of nanofluid in CPMs and major mechanism for rejecting BTEX from aqueous solutions.

four possible pathways including transport along CNT surface, direct permeation through membrane pores, transport through the cavity pores of CNTs, transport through the aggregated pores and hydrophobic effect [14] [32]. The BTEX were rejected by pore due to size exclusion to reject and thus make the fast separation of BTEX from aqueous solutions. These results reflect that the 10-CPMs possess good potential applications in the separation of the BTEX form aqueous solutions.

\section{Conclusion}

This article studied the characteristics of PM and CPMs and their separation performance of BTEX from aqueous solutions. The rejection coefficients $(R)$ of BTEX were dependent of the CNT content of CPM, pore size of membrane, molecule size of BTEX, permeation pressure $(P)$, feed concentration $\left(C_{\mathrm{f}}\right)$ and temperature, but has no significant influence on ionic strength $(\mu)$. The size exclusion plays the important roles on BTEX separation by CPMs. It reveals that the higher molecule size, the higher rejection. The 10-CPM behaved the better separation performance of BTEX with removal efficiencies of $80.3 \%, 84.7 \%, 88.5 \%$ and $90.0 \%$, respectively, under the relatively lower pressure 10 psi. It has not only higher water flux but also the relatively higher $R$ as comparing of $5 \%$ and $15 \%$ CNT of CPM. The majority pore size of 10 -CPM was $<0.4$ $\mathrm{nm}$ that is capable for removing BTEX which have molecule size $<0.58 \mathrm{~nm}$. This suggests that the 10-CPMs possess good potential for BTEX removal in wastewater treatment.

\section{Acknowledgements}

Support from the National Science Council, Taiwan, under a contract no. of NSC972221-E-005-036-MY3 is gratefully acknowledged. 


\section{References}

[1] Eckenfelder Jr., W.W. (1989) Industrial Water Pollution Control, Singapore. McGraw-Hill, Singapore.

[2] Holt, J.K., Park, H.G., Wang, Y., Stadermann, M., Artyukhin, A.B., Grigoropoulos, C.P., Noy, A. and Bakajin, O. (2006) Fast Mass Transport Through Sub-2-Nanometer Carbon Nanotubes. Science, 312, 1034-1037. http://dx.doi.org/10.1126/science.1126298

[3] Fornasiero, F., Park, H.G., Holt, J.K., Stadermann, M., Grigoropoulos, C.P., Noy, A. and Bakajin, O. (2008) Mechanism of Ion Exclusion by Sub-2nm Carbon Nanotube Membranes. Materials Research Society Symposium Proceedings, 1106, 1106-PP1103-1103. http://dx.doi.org/10.1557/proc-1106-pp03-03

[4] Fornasiero, F., Park, H.G., Holt, J.K., Stadermann, M., Grigoropoulos, C.P., Noy, A. and Bakajin, O. (2008) Ion Exclusion by Sub-2-nm Carbon Nanotube Pores. Proceedings of the National Academy of Sciences, 105, 17250-17255. http://dx.doi.org/10.1073/pnas.0710437105

[5] Guo, S., Meshot, E.R., Kuykendall, T., Cabrini, S. and Fornasiero, F. (2015) Nanofluidic Transport through Isolated Carbon Nanotube Channels: Advances, Controversies, and Challenges. Advanced Materials, 27, 5726-5737. http://dx.doi.org/10.1002/adma.201500372

[6] Hummer, G., Rasaiah, J.C. and Noworyta, J.P. (2001) Water Conduction through the Hydrophobic Channel of a Carbon Nanotube. Nature, 414, 188-190.

http://dx.doi.org/10.1038/35102535

[7] Kim, S., Pechar, T.W. and Marand, E. (2006) International Congress on Membranes and Membrane Processes Poly(imide siloxane) and Carbon Nanotube Mixed Matrix Membranes for Gas Separation. Desalination, 192, 330-339.

http://dx.doi.org/10.1016/j.desal.2005.03.098

[8] Holt, J.K., Noy, A., Huser, T., Eaglesham, D. and Bakajin, O. (2004) Fabrication of a Carbon Nanotube-Embedded Silicon Nitride Membrane for Studies of Nanometer-Scale Mass Transport. Nano Letters, 4, 2245-2250. http://dx.doi.org/10.1021/nl048876h

[9] Majumder, M., Chopra, N., Andrews, R. and Hinds, B.J. (2005) Nanoscale Hydrodynamics: Enhanced Flow in Carbon Nanotubes. Nature, 438, 44-44. http://dx.doi.org/10.1038/438044a

[10] Kim, S., Jinschek, J.R., Chen, H., Sholl, D.S. and Marand, E. (2007) Scalable Fabrication of Carbon Nanotube/Polymer Nanocomposite Membranes for High Flux Gas Transport. Nano Letters, 7, 2806-2811. http://dx.doi.org/10.1021/nl071414u

[11] Corry, B. (2008) Designing Carbon Nanotube Membranes for Efficient Water Desalination. The Journal of Physical Chemistry B, 112, 1427-1434. http://dx.doi.org/10.1021/jp709845u

[12] Joseph, S. and Aluru, N.R. (2008) Why Are Carbon Nanotubes Fast Transporters of Water? Nano Letters, 8, 452-458. http://dx.doi.org/10.1021/nl072385q

[13] Thomas, J.A. and McGaughey, A.J.H. (2008) Reassessing Fast Water Transport through Carbon Nanotubes. Nano Letters, 8, 2788-2793. http://dx.doi.org/10.1021/nl8013617

[14] Goh, P.S., Ismail, A.F. and Ng, B.C. (2013) Carbon Nanotubes for Desalination: Performance Evaluation and Current Hurdles. Desalination, 308, 2-14. http://dx.doi.org/10.1016/j.desal.2012.07.040

[15] Blöcher, C., Dorda, J., Mavrov, V., Chmiel, H., Lazaridis, N.K. and Matis, K.A. (2003) Hybrid Flotation-Membrane Filtration Process for the Removal of Heavy Metal Ions from Wastewater. Water Research, 37, 4018-4026. http://dx.doi.org/10.1016/S0043-1354(03)00314-2 
[16] Bessbousse, H., Rhlalou, T., Verchère, J.F. and Lebrun, L. (2008) Removal of Heavy Metal Ions from Aqueous Solutions by Filtration with a Novel Complexing Membrane Containing Poly(Ethyleneimine) in a Poly(Vinyl Alcohol) Matrix. Journal of Membrane Science, 307, 249-259. http://dx.doi.org/10.1016/j.memsci.2007.09.027

[17] Mostafavi, S.T., Mehrnia, M.R. and Rashidi, A.M. (2009) Issues 1 and 2: First International Workshop between the Center for the Seawater Desalination Plant and the European Desalination Society Preparation of Nanofilter from Carbon Nanotubes for Application in Virus Removal from Water. Desalination, 238, 271-280. http://dx.doi.org/10.1016/j.desal.2008.02.018

[18] Shawky, H.A., Chae, S.-R., Lin, S. and Wiesner, M.R. (2011) Synthesis and Characterization of a Carbon Nanotube/Polymer Nanocomposite Membrane for Water Treatment. Desalination, 272, 46-50. http://dx.doi.org/10.1016/j.desal.2010.12.051

[19] Bakajin, O., Noy, A., Fornasiero, F., Grigoropoulos, C.P., Holt, J.K., In, J.B., Kim, S. and Park, H.G. (2014) Chapter 11: Nanofluidic Carbon Nanotube Membranes: Applications for Water Purification and Desalination. In: Sustich, R., Duncan, J. and Savage, N., Eds., Nanotechnology Applications for Clean Water, 2nd Edition, William Andrew Publishing, Oxford, 173-188. http://dx.doi.org/10.1016/B978-1-4557-3116-9.00011-1

[20] Kim, J.-H. and Lee, S.-H. (2002) Molecular Dynamics Simulation Studies of Benzene, Toluene, and $p$-Xylene in a Canonical Ensemble. Bulletin of the Korean Chemical Society, 23, 441-446. http://dx.doi.org/10.5012/bkcs.2002.23.3.441

[21] Zhai, G., Ying, L., Kang, E.T. and Neoh, K.G. (2002) Poly(Vinylidene Fluoride) with Grafted 4-Vinylpyridine Polymer Side Chains for $\mathrm{pH}$-Sensitive Microfiltration Membranes. Journal of Materials Chemistry, 12, 3508-3515. http://dx.doi.org/10.1039/b206486c

[22] Su, F., Lu, C. and Chen, H.-S. (2011) Adsorption, Desorption, and Thermodynamic Studies of CO2 with High-Amine-Loaded Multiwalled Carbon Nanotubes. Langmuir, 27, 80908098. http://dx.doi.org/10.1021/la201745y

[23] Dresselhaus, M.S., Dresselhaus, G. and Saito, R. (1995) NanotubesPhysics of Carbon Nanotubes. Carbon, 33, 883-891. http://dx.doi.org/10.1016/0008-6223(95)00017-8

[24] Saito, Y., Yoshikawa, T., Bandow, S., Tomita, M. and Hayashi, T. (1993) Interlayer Spacings in Carbon Nanotubes. Physical Review B, 48, 1907-1909.

http://dx.doi.org/10.1103/PhysRevB.48.1907

[25] Su, F., Lu, C. and Hu, S. (2010) Adsorption of Benzene, Toluene, Ethylbenzene and p-Xylene by NaOCl-Oxidized Carbon Nanotubes. Colloids and Surfaces A: Physicochemical and Engineering Aspects, 353, 83-91.

http://dx.doi.org/10.1016/j.colsurfa.2009.10.025

[26] Luo, M.-L., Zhao, J.-Q., Tang, W. and Pu, C.-S. (2005) Hydrophilic Modification of Poly(ether Sulfone) Ultrafiltration Membrane Surface by Self-Assembly of $\mathrm{TiO}_{2}$ Nanoparticles. Applied Surface Science, 249, 76-84. http://dx.doi.org/10.1016/j.apsusc.2004.11.054

[27] Miyauchi, M., Kieda, N., Hishita, S., Mitsuhashi, T., Nakajima, A., Watanabe, T. and Hashimoto, K. (2002) Reversible Wettability Control of $\mathrm{TiO}_{2}$ Surface by Light Irradiation. Surface Science, 511, 401-407. http://dx.doi.org/10.1016/S0039-6028(02)01551-0

[28] Vrijenhoek, E.M., Hong, S. and Elimelech, M. (2001) Influence of Membrane Surface Properties on Initial Rate of Colloidal Fouling of Reverse Osmosis and Nanofiltration Membranes. Journal of Membrane Science, 188, 115-128. http://dx.doi.org/10.1016/S0376-7388(01)00376-3

[29] Al-Jeshi, S. and Neville, A. (2006) An Investigation into the Relationship between Flux and Roughness on RO Membranes Using Scanning Probe Microscopy. Selected Paper from the 
10th Aachen Membrane Colloquium. Desalination, 189, 221-228.

http://dx.doi.org/10.1016/j.desal.2005.08.001

[30] Escobar, I.C., Hong, S. and Randall, A.A. (2000) Removal of Assimilable Organic Carbon and Biodegradable Dissolved Organic Carbon by Reverse Osmosis and Nanofiltration Membranes. Journal of Membrane Science, 175, 1-17. http://dx.doi.org/10.1016/S0376-7388(00)00398-7

[31] Sharma, R.R. and Chellam, S. (2006) Temperature and Concentration Effects on Electrolyte Transport across Porous Thin-Film Composite Nanofiltration Membranes: Pore Transport Mechanisms and Energetics of Permeation. Journal of Colloid and Interface Science, 298, 327-340. http://dx.doi.org/10.1016/j.jcis.2005.12.033

[32] Gethard, K., Sae-Khow, O. and Mitra, S. (2011) Water Desalination Using Carbon-Nanotube-Enhanced Membrane Distillation. ACS Applied Materials \& Interfaces, 3, 110-114. http://dx.doi.org/10.1021/am100981s

Submit or recommend next manuscript to SCIRP and we will provide best service for you:

Accepting pre-submission inquiries through Email, Facebook, LinkedIn, Twitter, etc. A wide selection of journals (inclusive of 9 subjects, more than 200 journals)

Providing 24-hour high-quality service

User-friendly online submission system

Fair and swift peer-review system

Efficient typesetting and proofreading procedure

Display of the result of downloads and visits, as well as the number of cited articles Maximum dissemination of your research work

Submit your manuscript at: http://papersubmission.scirp.org/

Or contact jwarp@scirp.org 